\title{
Spring-driven high speed valve for massive gas injection in tokamaks
}

\author{
M. Dibon ${ }^{a, b}$, K. Mank ${ }^{a}$, G. Pautasso ${ }^{a}$, M. Griener ${ }^{a, b}$, A. Herrmann ${ }^{a}$, V. Mertens ${ }^{a}$, R. Neu ${ }^{a, b}$, B. Ploeckl ${ }^{a}$, \\ V. Rohde ${ }^{a}$ \\ ${ }^{a}$ Max-Planck-Institute for Plasma Physics, Boltzmannstr. 2, 85748 Garching, Germany \\ ${ }^{b}$ Technical University Munich, Boltzmannstr. 15, 85748 Garching, Germany
}

A new high speed gas valve was developed for disruption mitigation studies in the tokamak ASDEX Upgrade. The valve was designed to operate inside the vacuum vessel to reduce the time of flight of the injected gas and to prevent dispersion of the gas cloud before the gas reaches the plasma. A spring-driven mechanism was chosen for the valve as it is robust against the high magnetic fields and electromagnetic disturbances inside the vessel. The internal gas reservoir $\left(128 \mathrm{~cm}^{3}\right)$ of the valve, which holds the mitigation gas, is opened within $1.5 \mathrm{~ms}$ and the maximal stroke between valve plate and nozzle (diameter $13 \mathrm{~mm}$ ) is $4.5 \mathrm{~mm}$. This allows a peak flow rate of $72 \mathrm{kPam} / \mathrm{s}$ after $1 \mathrm{~ms}$ which was determined both analytically and numerically. The highest gas velocity (approx. $560 \mathrm{~m} / \mathrm{s}$ ) is reached $0.6 \mathrm{~ms}$ after the valve is opened. The gas cloud expands in pear shape with an opening angle of $49^{\circ}$.

Keywords: massive gas injection, disruption mitigation, piezo valve, ASDEX Upgrade

\section{INTRODUCTION}

Disruptions are a major problem for the safe operation of tokamaks. At high thermal energy they can cause concentrated heat loads on plasma facing components which then result in heavy damage. Additionally, elongated plasmas are vertically unstable and their position is feedback controlled by the plasma control system. Large plasma parameter perturbations (like the ones occurring during a disruption) and plasma shape outside the controllability region result in the growth of the instability. This induces eddy currents and halo currents are driven in the conductive structures, resulting in huge mechanical forces ${ }^{1}$. Furthermore, the current quench produces significant electrical fields in the plasma, which themselves can accelerate electrons up to relativistic speeds ${ }^{2}$ depending on the plasma density and current. These electrons transfer energy by collisions to slower electrons causing an avalanche of secondary runaway electrons (REs). If the beam of REs loses confinement, it can deposit its energy on a narrow area, damaging the first wall ${ }^{3}$. 
Mitigating these destructive effects is therefore of great importance for the safe operation of tokamaks. A reliable mitigation method is massive gas injection (MGI). It has proven to be effective on several different machines like ASDEX Upgrade ${ }^{4}$, Alcator C-Mod ${ }^{5}$, DIII-D-8, ${ }^{6-8} T^{9,10}, \mathrm{MAST}^{11}, \mathrm{TEXTOR}^{12}$ and Tore Supra ${ }^{13}$. Peak heat loads are significantly reduced by distributing the radiated power over a larger area; induced currents are depend on the current decay rate which is linked to the amount of injected material and mitigation of REs has been shown at DIII-D and ASDEX Upgrade ${ }^{14}$.

The most commonly used injection technology for MGI employs fast gas valves. These valves allow the injection of massive amounts of gas within milliseconds into the plasma vessel. Most of the valves are electromagnetic valves ${ }^{15}$ which are robust and reliable but too large to be installed in the vacuum vessel of ASDEX Upgrade (AUG) on the magnetic high field side behind the heat shield. Close proximity to the plasma has proven to grant a better assimilation of the impurity atoms into the plasma $^{16}$. This allows the use of smaller amounts of impurity atoms, which is favorable for the vacuum pumping system, without compromising the mitigation ability. Hence, a small valve had to be designed which was able to withstand the strong magnetic field (max. 3.1 T), the UHV conditions and the baking temperature $\left(150^{\circ} \mathrm{C}\right)$ of the vessel.

A new type of spring-driven valve was developed for AUG to replace prototype spring valves which showed unsatisfactory reliability. Since the valves are installed inside the vacuum vessel of AUG, accessibility is limited to the maintenance phases. Hence, a reliable operation of the valves is of upmost importance. The prototype valves were retrieved from AUG and analyzed to determine the weak spots that lead to failure. It was found that the calibration of the piezoelectric stack actuators had changed during assembly. Furthermore the valve seal which was vulcanized into the valve plate had deteriorated due to splinters created during manufacturing. The switches used for position detection had not survived the baking temperatures, the clamps which hold the valve stem were too stiff to balance uneven expansion of the piezoelectric stacks and therefore the round ceramic stem showed signs of uneven wear. From this information a complete redesign was made, based on the operating principle of the old valves. This paper comprises the basic valve design with special emphasis on active components, the CFD model used to determine the gas flow from the valve into the vacuum vessel as well as the results of the tests with the new valve. 
It is foreseen to install two new spring-driven valves in AUG, one on the magnetic low field side and one opposite on the magnetic high field side. Together with an older spring-driven valve and a recently developed piezo-driven valve ${ }^{17}$, they will complete the in-vessel MGI system of AUG for 2017.

\section{VALVE DESIGN}

The design specifications are governed by the physics requirements to mitigate disruptions and by environmental requirements due to the location of the valve inside the vacuum vessel. From the physics point of view the opening time of the valve, the total amount of injected material and the mass flow rate of the gas are the most important design factors. It has proven preferable to inject the impurities during the pre-TQ phase for an efficient mitigation of thermal loads and forces ${ }^{16}$. This phase is of the order of milliseconds; hence the valve has to release the gas on the same timescale. An opening time of $2 \mathrm{~ms}$ was accepted as reasonable compromise between the physical needs and the technical effort. The amount of injected material is given by the volume of the valves gas reservoir, the reservoir pressure and the gas temperature. As the gas temperature can be assumed to be at room temperature inside the valve, the number of particles is determined by volume and pressure. To allow a wide range of experiments, the valve was designed with a reservoir of $128 \mathrm{~cm}^{3}$ which can hold pressures of up to $5 \mathrm{MPa}$, equaling $1.5^{*} 10^{23}$ particles. Environmental requirements are set by the invessel conditions. Compatibility with the UHV conditions is imperative, meaning an overall leak rate must be below $10^{-3} \mathrm{Pam}^{3} / \mathrm{s}$, including in-vessel gas lines. This also limits the usable materials especially in view of the vessel baking which takes place at $150^{\circ} \mathrm{C}$. The valve materials must not show strong degassing or deform at this temperature. Furthermore the valve must be resistant against magnetic fields and must create none itself. The spring-driven valve fulfills both physical and environmental requirements and is suitable for in-vessel operation. It is manufactured from stainless steel, ceramic and viton. The main components are illustrated in Fig 1. 


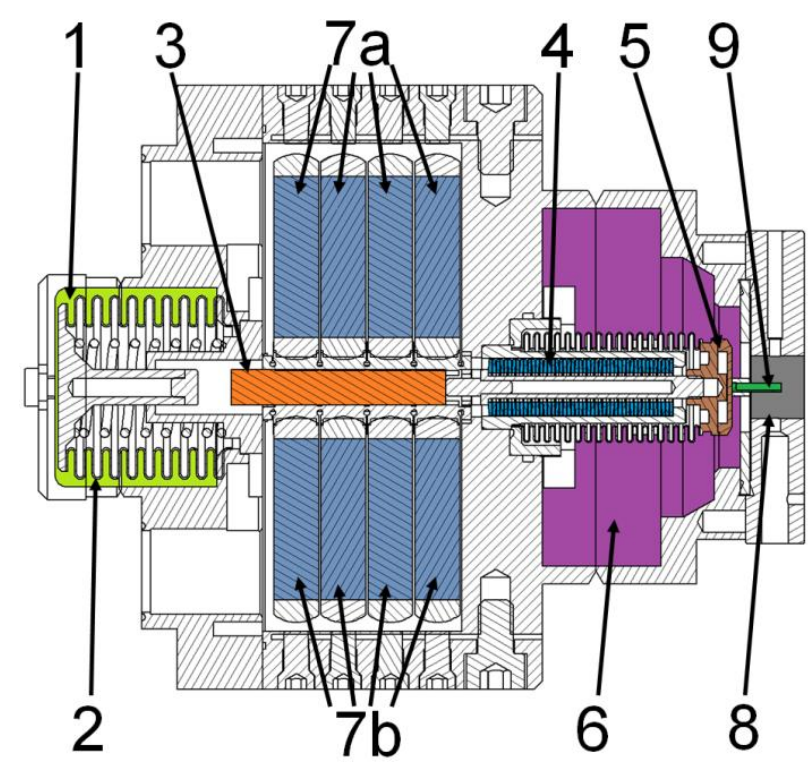

Figure 1: Structure of the valve depicting the main components: Rear gas volume (1), rear bellow (2), ceramic valve stem (3), stack of disc springs (4), valve plate (5), main gas reservoir (6), piezoelectric stack actuators $(7 \mathrm{a}, 7 \mathrm{~b})$, the nozzle $(8)$ and the wedge for position detection (9)

Compressed air at 1.5 MPa is applied to the rear volume (1) where the rear bellow (2) is mounted. The air compresses the bellow, pushing the ceramic valve stem (3) forward, compressing the stack of disc springs (4) and pressing the conical $\left(30^{\circ}\right)$ valve plate (5) into the viton seal, closing the gas reservoir (6) gas-tight. A DC voltage of $120 \mathrm{~V}$ is applied to eight piezoelectric stack actuators $(7 \mathrm{a}, 7 \mathrm{~b})$, four on each side of the valve stem. The actuators expand, clamping the valve stem. The compressed air is released from the rear volume and the actuators hold the stem in place. The mitigation gas can then be let into the gas reservoir, which can hold $128 \mathrm{~cm}^{3}$, with a maximum pressure of $5 \mathrm{MPa}$. When the valve is triggered, the piezoelectric stack actuators are discharged, they contract within $1 \mathrm{~ms}$ and the stem is released. The stack of disc springs relaxes and accelerates the stem and the valve plate backwards in $1.5 \mathrm{~ms}$ until they reach the maximum stroke of $4.5 \mathrm{~mm}$, opening the gas reservoir. The mitigation gas is purged into the plasma vessel through the straight nozzle (8) with a circular opening of $13 \mathrm{~mm}$ diameter.

\section{A. Disc springs}

Disc springs were chosen as actuator for the valve because they allow a high spring rate relative to their mass and the required space. The stack of disc springs consists of 47 Schnorr $002700 \mathrm{~A}^{18}$ discs, each with an outer diameter of $12.5 \mathrm{~mm}$, an inner diameter of $6.2 \mathrm{~mm}$, a thickness of $0.7 \mathrm{~mm}$ and a free stroke of $0.3 \mathrm{~mm}$. The stack is assembled from pairs of discs in column configuration with a single disc at the end. This structure ensures that the stiffness of the stack remains constant while the 
effective stroke is increased. The spring force $F$ in $\mathrm{N}$ is given as function of the stroke $s$ in $\mathrm{mm}$ using empirical factors given by the manufacturer.

$$
F(s)=0.034 \frac{N}{m^{3}} * s^{3}-1.29 \frac{N}{m^{2}} * s^{2}+72.2 \frac{N}{m m} * s
$$

The force of the stack of disc springs is compared to the force of one disc in Fig. 2 as a function of the stroke $s$. The discs are made from stainless steel 1.4301 , hence the stack has a total mass of $0.024 \mathrm{~kg}$ and an effective accelerated mass of $0.008 \mathrm{~kg}$.

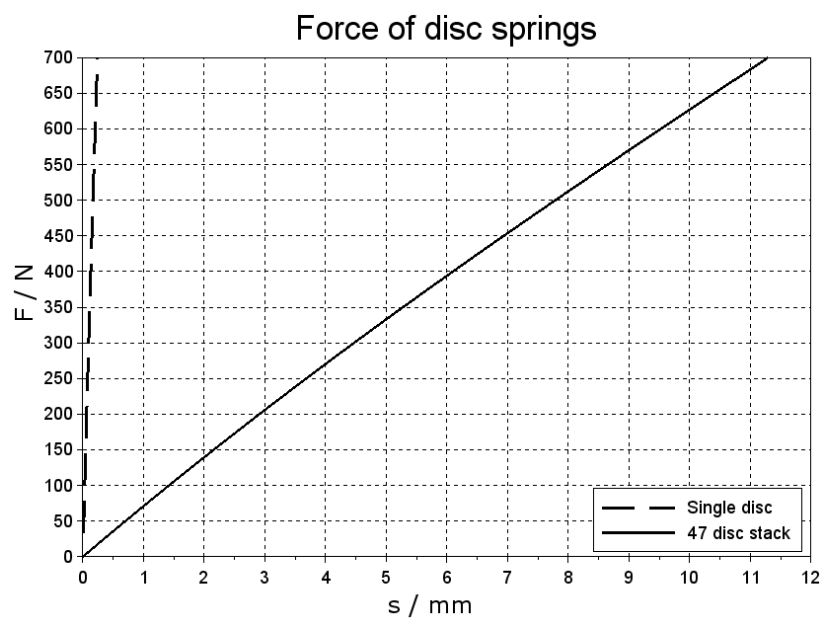

Figure 2: Calculated force $\mathrm{F}$ in $\mathrm{N}$ of a single disc and force of the stack vs. stroke $s$ in $\mathrm{mm}$

\section{B. Bellows}

The rear bellow, which is compressed by the air at $1.5 \mathrm{MPa}$ is a Witzenmann BAA $27 \times 41 \times 2 \times 0.2^{19}$ with eight corrugations and an hydraulic area of $9.1 \mathrm{~cm}^{2}$. The upper pressure limit is $3.2 \mathrm{MPa}$, which corresponds to a maximum transferred force of $2912 \mathrm{~N}$ or $1365 \mathrm{~N}$ for the operating pressure of 1.5 $\mathrm{MPa}$. The axial stiffness is $32.5 \pm 10 \mathrm{~N} / \mathrm{mm}$ which corresponds to an upper force limit of $191 \mathrm{~N}$ at the maximal stroke of $4.5 \mathrm{~mm}$. A plate with a bolt is welded onto the free end of the bellow. The other end is welded into the valve cap. When pressurized air is let into the rear volume, the bellow compresses and the bolt pushes the ceramic stem. When the air is vented from the rear volume, the bellow detaches from the stem and moves back into its former position, creating a distance between bolt and stem which corresponds to the stroke of the valve. Thus, the bellow is not accelerated during opening of the valve and its mass can be neglected.

The front bellow is installed to relieve the valve plate from the pressure of the mitigation gas. Hence the springs do not have to overcome the pressure force while accelerating the valve plate. The bellow 
is a Witzenmann BAA $16.8 \times 24 \times 2 \times 0.15^{19}$ with 17 corrugations and a hydraulic area of $3.25 \mathrm{~cm}^{2}$. This allows a circular diameter of the sealing edge of $20.3 \mathrm{~mm}$. The stiffness of the bellow is $24.7 \pm 7.4$ $\mathrm{N} / \mathrm{mm}$. The bellow is installed as such, that it is stress free in the open state. Hence the spring force of the bellow, which accounts for $78 \mathrm{~N}$ at a stroke of $4.5 \mathrm{~mm}$, adds to the force of the disc springs. The fixed end of the front bellow is sealed off from the valve body by a viton O-ring and the free end is welded to the valve plate. Both bellows are made from stainless steel 1.4571 which leads to a total mass of $0.021 \mathrm{~kg}$ for the front bellow corresponding to an effective mass of $0.007 \mathrm{~kg}$.

\section{Valve stem}

The valve stem is a rectangular bar $8 \mathrm{~mm} \times 8 \mathrm{~mm} \times 48 \mathrm{~mm}$ made of sintered ceramic. The material used is a Buntenkötter Alsint 99.7 composed of $99.7 \% \mathrm{Al}_{2} \mathrm{O}_{3}$. The ceramic was chosen because it displays certain benefits over stainless steel in respect to thermal stability, stiffness and weight. The thermal expansion coefficient is $8.1 \times 10^{-6} \mathrm{~K}^{-1}$. The elasticity of the sintered stem is $370 \mathrm{GPa}$ and the mean density of the ceramic is $3.93 \mathrm{~g} / \mathrm{cm}^{3}$ which corresponds to a total mass of $0.0104 \mathrm{~kg}$. In addition it is highly wear resistant.

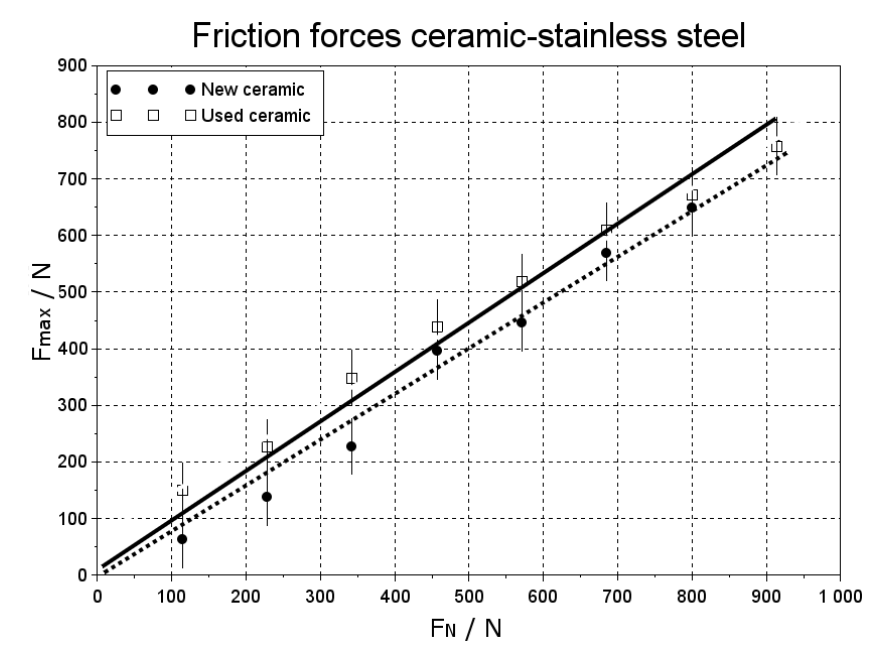

Figure 3: Peak friction force $F_{\max }$ between the ceramic stem and stainless steel as a function of the lateral force $F_{N}$

The stem has to be fixed by the charged piezoelectric actuators and the flexible stainless steel clamps. Hence, the static friction force must be higher than the combined forces of the disc springs and the front bellow. The static friction coefficient was therefore measured using the following simple arrangement which resembles the setup in the valve. The ceramic was clamped between two stainless steel plates, similar to the assembly in the valve and the clamping force $F_{N}$ was measured by a load cell. A force transducer was then pressed against the ceramic until it began to slide. The recorded analogue signal from the transducer indicated a peak in the parallel force directly before the onset of 
the movement. This value was used to define $F_{\max }$. Linear dependencies are clearly visible in Fig. 3 between the lateral force $\mathrm{F}_{\mathrm{N}}$ and the peak friction force $F_{\max }$, indicating constant static friction coefficients with values of 0.78 for the new ceramic and 0.91 for the old ceramic. It is assumed that the static friction coefficient increases slightly (Fig. 3) due to wear at both the plates and the ceramic which increases the surface roughness on the components.

\section{Piezoelectric stack actuators}

The piezoelectric stack actuators responsible for securing the valve stem in the closed position are of the type $\mathrm{P}-888.91^{20}$ manufactured by piceramic. The stacks are assembled from several quadratic ceramic plates which are glued together until the stack measures $10 \mathrm{~mm} \times 10 \mathrm{~mm} \times 36 \mathrm{~mm}$. The maximal elongation depends on the number of layers, hence the height of the stack. The blocking force, meaning the force at zero elongation is related to the cross-sectional area. For this type of stack, the blocking force amounts to $3800 \mathrm{~N}$ and the elongation to $0.038 \pm 0.008 \mathrm{~mm}$ when the maximal voltage of $120 \mathrm{~V}$ is applied. The force decreases linearly with the elongation until it reaches zero at the upper stroke limit. Due to the limited precision during the installation, the stacks have to be adjusted after the valve is assembled. This is possible using M6 screws with fine thread which are placed in the valve body and are accessible from outside. Each stack has its own screw for individual adjustment. The screws press onto a thin metal membrane which separates the stacks from the screws. This ensures that the interior of the valve body remains a vacuum tight closed volume.

The disc springs and the front bellow generate a combined force of $446 \mathrm{~N}$ in the closed state. With a static friction coefficient of 0.78 for the new ceramic stem, a total perpendicular force of $572 \mathrm{~N}$ is required to secure the stem; hence each stack has to exert $71.5 \mathrm{~N}$. This allows a free stroke equivalent to $98 \%$ of the maximum stroke of the actuators to be used, which is enough for a free movement of the stem once the stacks are discharged. The material used is sintered Lead Zirconate Titanate (PZT) which upholds its piezoelectric performance up to temperatures of $150{ }^{\circ} \mathrm{C}$. It is not influenced by magnetic fields or low pressure environments and is therefore a suitable material for invessel applications. 


\section{E. Main valve sealing}

The main valve sealing separates the gas reservoir from the nozzle. It is a ring shaped viton plate with an outer diameter of $48 \mathrm{~mm}$ and an inner diameter of $20 \mathrm{~mm}$ with a thickness of $2 \mathrm{~mm}$. The outer diameter and the thickness are chosen as such to allow the installation in a standard CF40 flange connection. The inner diameter corresponds to the hydraulic diameter of the front bellow. The simple design of the sealing allows fast manufacturing by stamping and quick installation.

\section{F. Nozzle}

The valve nozzle is a circular drilling in a standard CF40 flange with a diameter of $13 \mathrm{~mm}$. CFD simulations have shown, that different nozzle geometries have almost no effect on the gas velocity or the mass flow. The straight nozzle has a low manufacturing effort and its edges interrupt all direct lines of sight between the plasma and the viton seal. The throughput through the nozzle can be estimated by the compressible gas law in the critical flow cross-section and the ideal gas law in the reservoir.

\begin{tabular}{|c|c|}
\hline$\dot{m}(t)=\frac{p_{0}(t) * \sqrt{\gamma} * A(t)}{\sqrt{R_{s} * T_{0}}} *\left(\frac{\gamma+1}{2}\right)^{-\left(\frac{\gamma+1}{2 *(\gamma-1)}\right)}$ & (2) \\
\hline$\frac{\partial p_{0}(t)}{\partial t}=\dot{m}(t) * \frac{R_{s} * T_{0}}{V}$ & (3) \\
\hline
\end{tabular}

Here, $R_{s}$ and $Y$ are the specific gas constant and the adiabatic constant of the mitigation gas. $V$ specifies the volume of the reservoir and $T_{0}$ the gas temperature, which is assumed to remain constant in the reservoir. Since the valve plate is moving, the critical flow cross-section $A$ is changing over time.

\begin{tabular}{|c|c|}
\hline$A_{1}(t)=\pi * d_{s} * x(t)$ & (4) \\
\hline$A_{2}=\frac{\pi}{4} *{d_{n}}^{2}$ & (5) \\
\hline
\end{tabular}

$A_{1}$ is the lateral surface of a cylinder that is created by the inner diameter of the viton sealing $\left(d_{s}=20\right.$ $\mathrm{mm}$ ) and the distance $x$ of the sealing and the valve plate. $A_{2}$ is the cross-sectional area of the nozzle $\left(d_{n}=13 \mathrm{~mm}\right)$. Whatever area is smallest is recognized as critical flow area. The initial conditions were set that the mass flow is zero and the reservoir pressure is the desired pressure. Fig. 6 shows a solution using argon gas properties, an initial reservoir pressure of $5 \mathrm{MPa}$ and a linear movement of the valve plate of $2 \mathrm{~m} / \mathrm{s}$. The differential equation was solved in Scilab using an Euler forward 
formulation with a time step of $0.01 \mathrm{~ms}$. The mass flow is peaking at a value of $1.6 \mathrm{~kg} / \mathrm{s}$ after $1 \mathrm{~ms}$. This is roughly the point where the areas $A_{1}$ and $A_{2}$ are equally large. Hence one can state that the stroke of the valve plate must be at least large enough that area $A_{1}=A_{2}$. Otherwise the maximal throughput cannot be reached. However, increasing the stroke further does not influence the mass flow as the critical flow cross-section which limits the flow rate is located in the nozzle once $A_{1}>A_{2}$. It has to be noted that an investigation of a valve in Jülich ${ }^{21}$ showed a significantly higher flow velocity shortly after opening the valve than the quasi-stationary equations (2) and (3) would predict. An analytical explanation for this phenomenon is given. A measurement of the flow velocity was not performed for the spring-driven valve and thus this effect was not observed.

\section{G. Position detector}

Since the valve is installed inside the plasma vessel it is necessary to provide reliable information about the position of the valve plate in order to prevent flooding of the vessel. Therefore an optical setup is installed in the nozzle flange. This consists of a light source $(820 \mathrm{~nm})$ and an opposing receiver with a collimator lens. A metal bar $(2 \mathrm{~mm} \times 4 \mathrm{~mm} \times 11 \mathrm{~mm})$ with a triangular recess is mounted on top of the valve plate (Fig.1 (9)).

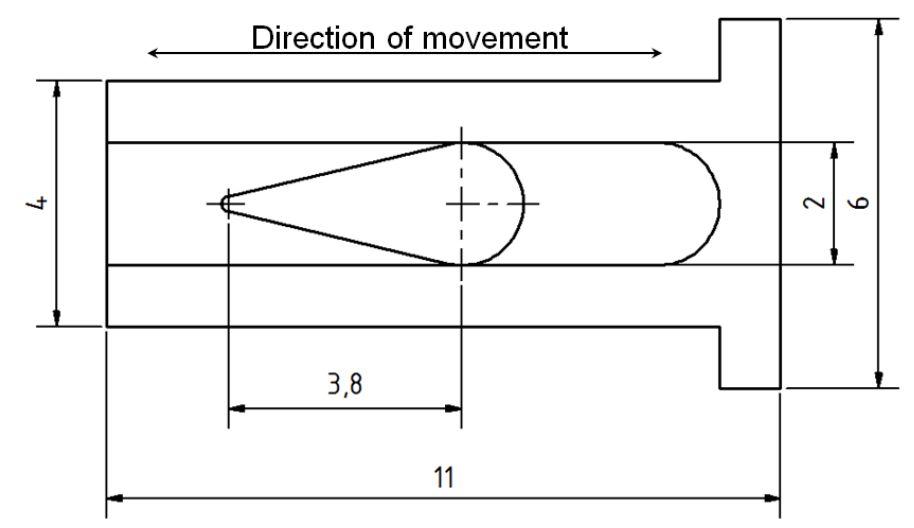

Figure 4: Metal bar $(2 \mathrm{~mm} \times 4 \mathrm{~mm} \times 11 \mathrm{~mm})$ with eroded triangular recess and $6 \mathrm{~mm}$ mounting socket

This bar is moved through the nozzle following the motion of the valve plate. In the open state the light beam is directed on the tip of the triangle, permitting only little light to pass through the recess. If the valve is closed, the beam passes through the wide end of the triangle allowing more light to reach the receiver. This light to and from the valve is conveyed by optical fibers inside and outside the vessel. The change in light intensity is measured using an amplified photocell. The system is designed as 
such, that a broken fiber generates a signal (received light intensity $=0$ ) equivalent to an open valve. Hence the control system blocks the gas inlet into the reservoir.

\section{CFD ANALYSIS}

In order to receive detailed data about the flow conditions and to check the analytic model presented in chapter II.F a CFD analysis was conducted using ANSYS Fluent. The 2D axisymmetric geometry (Fig. 5) was chosen to represent the gas reservoir, the nozzle, the valve plate with the bellow and the exterior space.

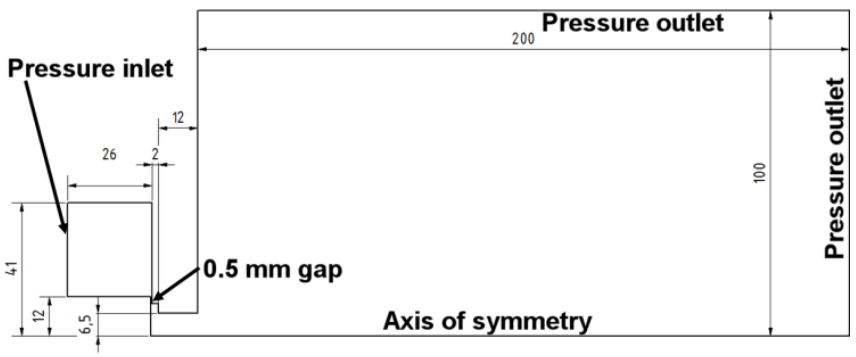

Figure 5: 2D axisymmetric model: Gas reservoir on the left, nozzle with $r=6.5 \mathrm{~mm}$ and the exterior space $200 \mathrm{~mm} \times 100 \mathrm{~mm}$. The pressure inlet is located on the far left boundary of the gas reservoir, the pressure outlets are on the top and right boundary of the expansion space.

The gap between the valve plate and the sealing edge measures $0.5 \mathrm{~mm}$. This is necessary because Fluent requires a continuous fluid volume. This geometry was meshed with a structured mesh composed of regular squares (edge length $0.5 \mathrm{~mm}$ ). Since the mesh would be deformed between the valve plate and the sealing, the mesh was refined in this region by a factor of two.

The simulation was set up as transient with a density based solver, which is better suited for supersonic flows. The energy equations were included in the solving process and the flow was defined as inviscid, which is acceptable for supersonic conditions. The entire domain was set to be argon as ideal gas and the wall boundaries were set to be aluminum. The left most boundary was defined as pressure inlet with a gas pressure of $5 \mathrm{MPa}$ and the outer right and upper boundaries as pressure outlet at a pressure of $0.0001 \mathrm{~Pa}$. Valve plate and bellow were set to perform a rigid body movement with a constant speed of $2 \mathrm{~m} / \mathrm{s}$ while the adjacent mesh should deform according to a linear elastic solid with a poisson ratio of 0.45 . The pressure inlet boundary changed its status at the beginning of the simulation to a wall boundary to prevent refilling of the reservoir. Reference values were calculated in relation to the conditions at the pressure inlet boundary. 
The formulations of the Navier-Stokes equations were set to be implicit for increased stability and the applicability of larger time steps. Hybrid initialization was chosen with a maximum residual of $10^{-8}$. This procedure evens the pressure distribution over the domain, which leads to the presence of gas in the nozzle at the onset of the simulation. However the computation of the first time steps run far more stable compared to cases with a steep pressure gradient at the sealing edge. The iterations for energy, velocity and continuity would stop when the smallest residual of the equations would drop to a value below $1 \times 10^{-3}$. The time step size was defined to be $5 \times 10^{-7} \mathrm{~s}$. This corresponds to a Courant number of 0.6 , which is stable with the implicit Euler formulation. The number of time steps was 20000, amounting to $10 \mathrm{~ms}$ of real time flow.

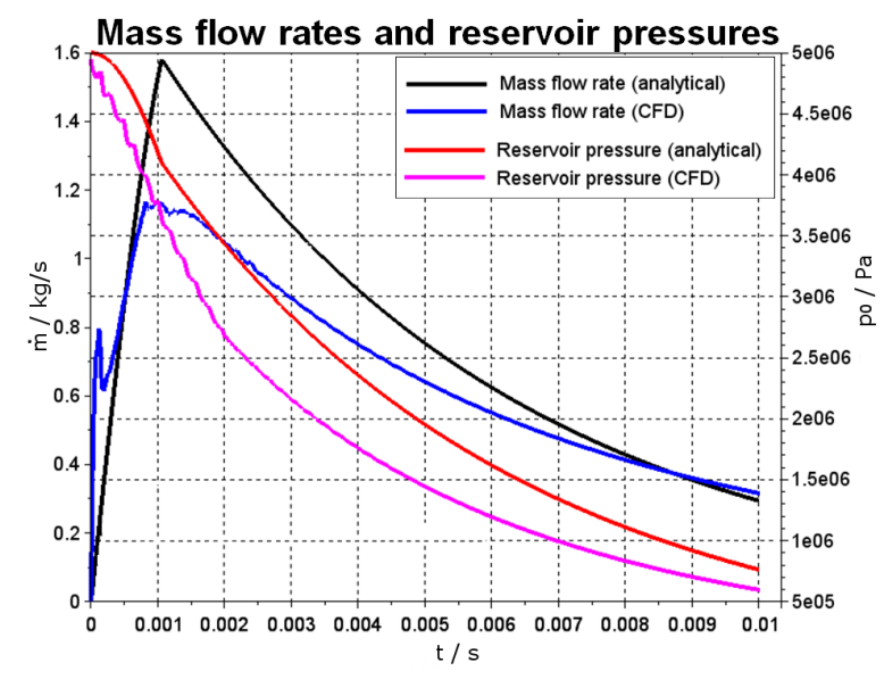

Figure 6: Evolution of the mass flow rate $\dot{m}$ and the reservoir pressure $p_{0}$ over time using the Ansys Fluent CFD model and the analytical model with $\mathrm{p}_{0}(\mathrm{t}=0)=5 \mathrm{MPa}$

Evolution of the mass flow rate and the reservoir pressure are comprised in Fig. 6 . The mass flow rate was measured at the exit plane of the nozzle. It peaks at a value of $1.2 \mathrm{~kg} / \mathrm{s}$ after $1 \mathrm{~ms}$, which is about $25 \%$ below the expected value of the ideal model. This discrepancy was found to be a result of neglected velocity and temperature profiles in the ideal model as well as a Mach number slightly above one at the critical surface in the simulation. However the moment of highest flow rate is identical with the model, proving the assumption that the critical surface changes as the valve opens. The peak after $0.3 \mathrm{~ms}$ is an artefact caused by the hybrid initialization and the initial gas pressure at the nozzle outlet. The pressure drop in the gas reservoir performs somewhat faster than anticipated although the final pressure value after $10 \mathrm{~ms}$ is almost identical to the predicted value. The steeper pressure gradient during the first time steps is due to the higher mass flow rate. 


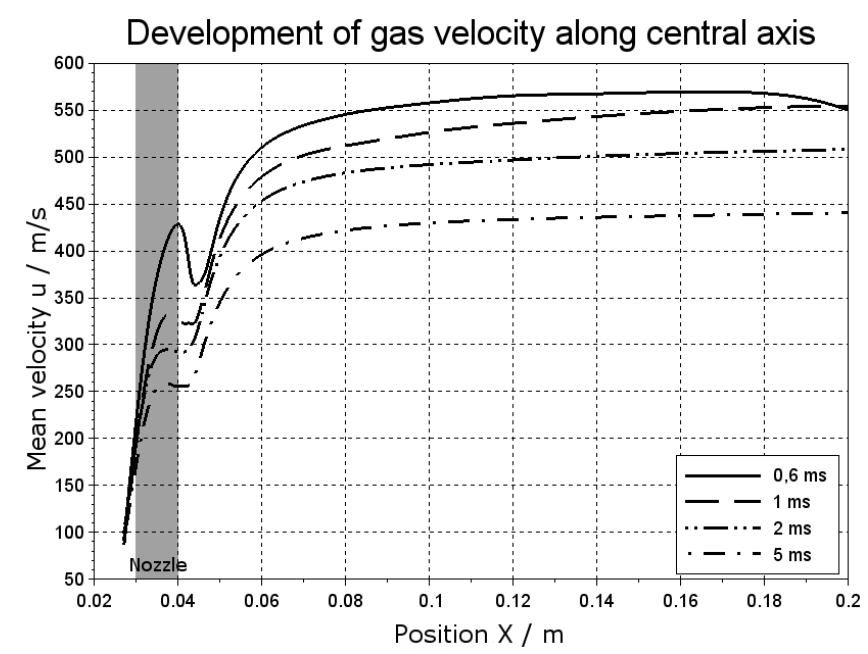

Figure 7: Mean gas velocity along the nozzle axis at different time steps

The mitigation gas expands into the vacuum vessel, which serves as divergent part of the valve nozzle, accelerating the gas until it reaches the maximum velocity at a $\mathrm{Ma}=2$. At the nozzle exit Mach numbers of the order of 1.3 are reached. Highest speeds are achieved directly at the onset of the stem movement. Primary reason for this is the cooling of the expanding gas, reducing the speed of sound. The distance from the nozzle exit where the highest speed is achieved increases over time as the pressure front propagates into the vessel (Fig. 7).

\section{TEST RESULTS}

The assembled valve prototype has undergone a series of thorough tests, to evaluate its performance and durability. Since its accessibility is limited once the valve is installed in the plasma vessel, all information concerning opening time, flow properties, evacuation time and deterioration has to be gathered beforehand.

\section{A. Opening time and stroke}

As outlined before, the opening time and the stroke in relation to the nozzle diameter are the limiting factors for the maximal flow rate, especially during the first millisecond after the valve is triggered (Fig. 7). To measure the movement of the valve plate, the valve was fixed to a stiff suspension. A calibrated fast laser displacement sensor was applied, with the laser beam pointing through the nozzle onto the valve plate. Both the analogue signal of the displacement sensor as the signal of the in-valve position detector were recorded on a fast oscilloscope, which was triggered by the discharge signal for the piezoelectric stack actuators. The analogue signal of the displacement sensor is calibrated to be 1 
$\mathrm{V} / \mathrm{mm}$. This allows the evaluation of the voltage output provided by the photocell, which varies between $1 \mathrm{~V}$ and $10 \mathrm{~V}$.

The signals of the position detector and the displacement sensor are in good agreement. A delay time of about $1 \mathrm{~ms}$ is visible in Fig. 8 , which is caused by the inertia of the piezoelectric stacks and the valve stem. The full stroke of $4.5 \mathrm{~mm}$ is reached after $2.7 \mathrm{~ms}$ which corresponds to a mean velocity of the valve plate of $1.67 \mathrm{~m} / \mathrm{s}$. The movement can be approximated well with a linear motion. After the maximum stroke is first reached the valve stem bounces back about $0.5 \mathrm{~mm}$ before returning to the final position. Since the stroke is large enough in respect to the orifice diameter, the bounce back does not influence the mass flow rate of the mitigation gas. The critical stroke, after which the nozzle becomes the critical cross-section, is $2.11 \mathrm{~mm}$, which is reached after $1.5 \mathrm{~ms}$. Hence the valve achieves the necessary stroke fast enough to fulfill its purpose and the position detector is suitable for operating the valve reliably.

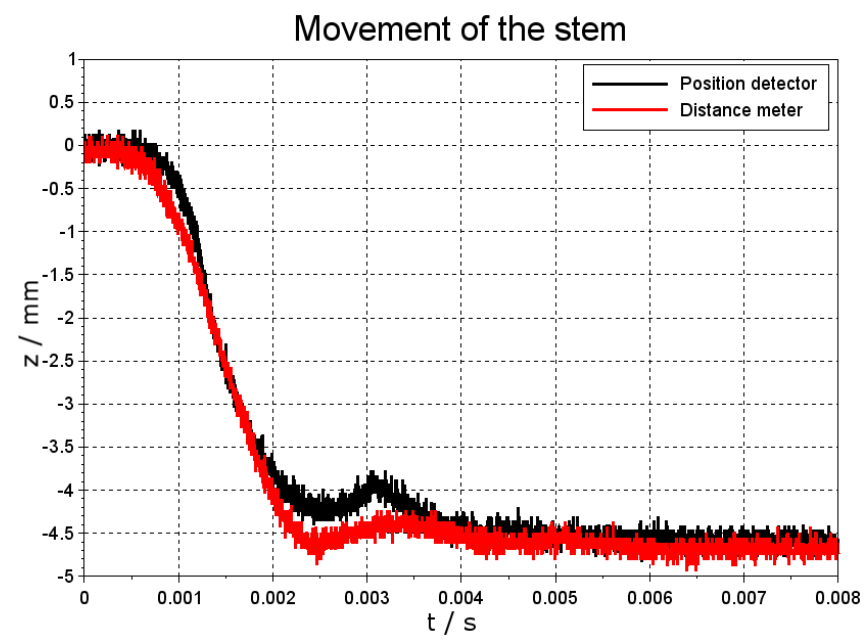

Figure 8: Time traces of the scaled signals from the position detector and the displacement sensor

\section{B. Gas expansion}

The gas expansion cloud outside the valve nozzle determines the region of the plasma edge where the cooling takes place strongest and hence where the radiation reaches its maximum during the prethermal quench phase. Additionally, the gas cloud could be taken as reference for experiments using a new fast camera in AUG, which observes the glow of the gas during disruption mitigation. Furthermore, the experiment was used to prove the assumption that the gas cloud does not expand too much on the short distance between valve and plasma when installed in the tokamak as this is a main reason for using in-vessel valves. Therefore this cloud was studied using the CFD analysis from 
sec. III and an experimental setup. The valve was fixed in the center of a $0.5 \mathrm{~m}^{3}$ vacuum vessel. A view port allows a line of sight perpendicular to the predicted flow axis. The fast camera ${ }^{22}$ for the observation was placed outside the window, recording the nozzle exit and a small region beyond the nozzle. For the test itself, a helium glow plasma at a pressure of $1.5 \mathrm{~Pa}$, a voltage of $314 \mathrm{~V}$ and a current of $2 \mathrm{~A}$ was generated inside the vacuum vessel. The gas chamber of the valve was filled with argon at a pressure of $5000 \mathrm{~Pa}$ which corresponds to a total inventory of $0.64 \mathrm{Pam}^{3}$ of $\operatorname{argon}^{\text {. The }}$ signal to open the valve was relayed to trigger the fast camera, which recorded the outflow of the argon gas into the glow discharge with a frame rate of $33000 \mathrm{fps}$.
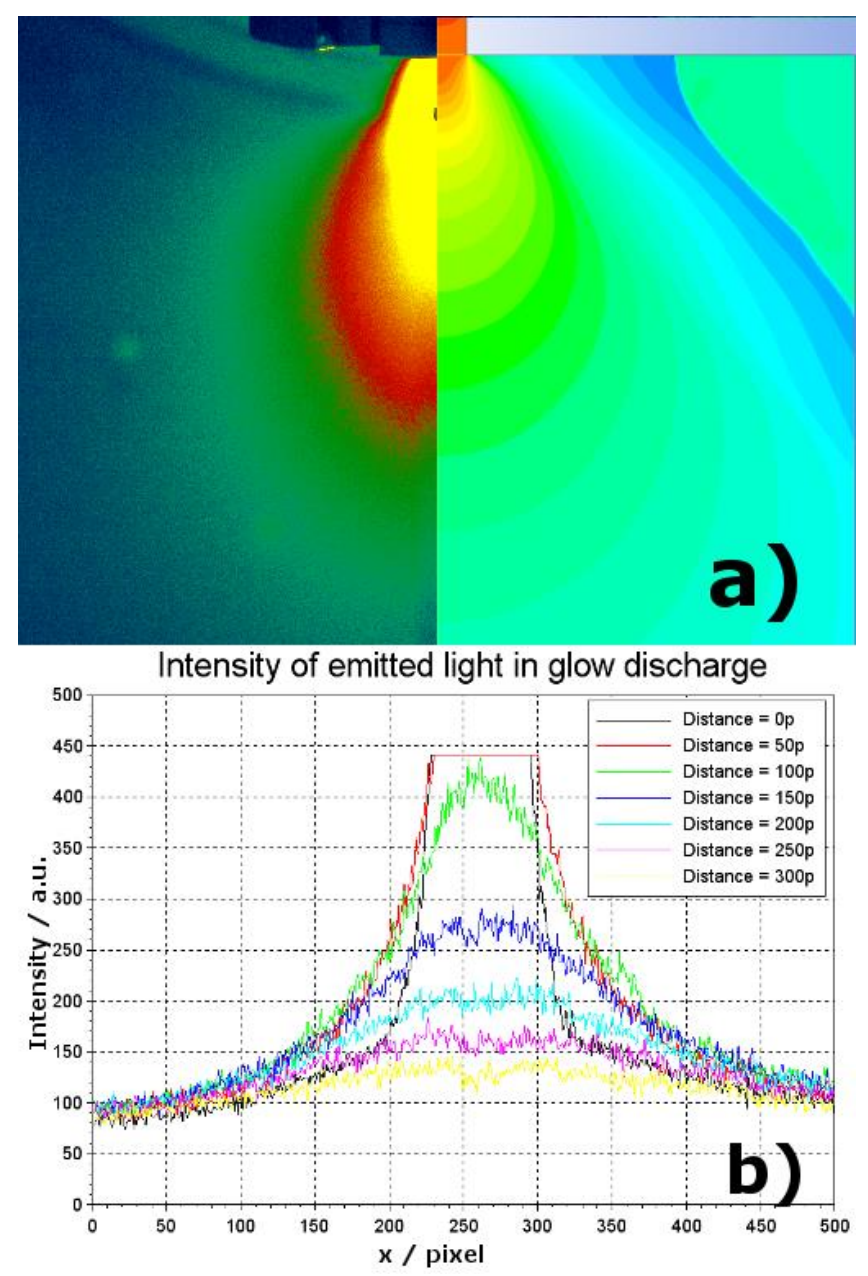

Figure 9: Gas expansion into helium glow plasma $0.28 \mathrm{~ms}$ after the trigger with the fast camera image on the left side and the CFD density distribution on the right (a) and the light intensity at different distances from the nozzle (b)

Fig. 9a shows the expansion cloud $0.28 \mathrm{~ms}$ after the valve was triggered. The conical shape is clearly visible as the argon glows brighter than the surrounding helium plasma. As the cone expands into the vacuum vessel the initial outflow angle becomes smaller forming a characteristic barrel shape. For a more thorough investigation the brightness of each pixel on horizontal lines through the cloud was 
used to measure the glow intensity distribution. The outline of the expansion cloud was defined where the intensity reaches half of its maximum value. Thus a point for the highest intensity and two points for the half intensity can be found for every distance to the nozzle exit. Since the glow intensity close to the nozzle is very high, the pixels of the fast camera go into saturation. Only for a distance above 100 pixels, the light intensity shows a clear maximum (Fig. 9b). The axis of highest intensity is well centered and is aligned with the predicted flow axis. The expansion cone is distributed symmetrically around this central axis. The angle between one of the outlines of the cone and the flow axis is largest at the nozzle exit at a value of $49^{\circ}$ and it decreases along the flow to a value of $22^{\circ}$, forming the barrel shape. This is in agreement with the CFD simulations although the computed angles close to the nozzle are on average $10^{\circ}$ smaller than the measured angles. This deviation decreases downstream.

The images further revealed that the particle density in the expansion cloud is not uniformly distributed. Shock waves form inside the cone mostly close to the nozzle exit. These can be recognized by bright and dark layers that occur periodically in the cone. Asymmetries in the glow intensity occurred shortly after the valve was triggered. This is due to a considerable amount of argon gas that had filled the tank, leading to discharges between the anode and the valve, distorting the contour of the glowing gas cloud in the images.

\section{Durability test}

Since the valves are installed inside the vessel, they have to perform reliably over long periods of time without maintenance or repairs. It was learned from previous experimental campaigns at AUG, that MGI valves undergo about 1000 operation cycles between maintenance breaks. A durability test was designed according to this normal number of employments. Therefore the valve was placed inside a vacuum vessel with a pumped volume of $0.229 \mathrm{~m}^{3}$. The valve was tested autonomously using a SIMATIC S7 control system which performed 1000 operational cycles. After this first phase of the test, the valve was baked at $150{ }^{\circ} \mathrm{C}$ for 7 days before performing another 1000 cycles. For each cycle the valve stem was pushed forward by $1.5 \mathrm{MPa}$ of compressed air and the gas reservoir was filled with 0.5 $\mathrm{MPa}$ of argon. The pressure curves recorded during the entire test series showed that the valve completed every cycle without malfunction or increase in leaking rate. The sealing edge of the viton showed signs of deterioration though. 


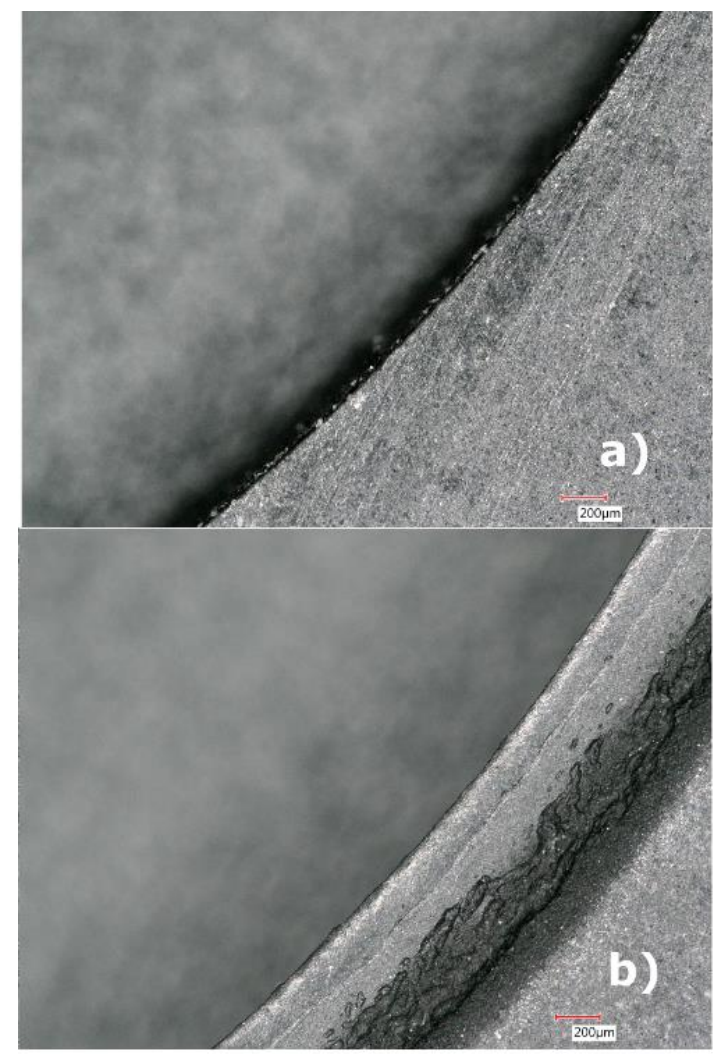

Figure 10: Viton sealing of the MGI valve before (a) and after (b) 2000 operation cycles

Images taken with a microscope clearly show the wear of the former sharp sealing edge. The conical valve plate scraped off material from the top of the sealing plate, compressed the lower part and deposited the scraped off material, which is the dark fissured zone in Fig. 10b, on top of the compressed plateau. Despite this deterioration, the leakage rate remained unchanged.

\section{CONCLUSION AND OUTLOOK}

A new type of spring-driven fast valve for massive gas injection has been developed, built and thoroughly tested. It is designed to be operated behind the heat shield inside on the magnetic high field side of the vacuum vessel of ASDEX Upgrade. Therefore it was built to withstand UHV conditions baking temperature of $150{ }^{\circ} \mathrm{C}$, ionizing radiation and magnetic fields. The valve fulfills the technical requirements of fast opening time $(1.5 \mathrm{~ms})$, sufficiently large gas inventory (max. $640 \mathrm{Pam}^{3}$ ) and fast evacuation time $(10 \mathrm{~ms})$ at maximal gas inventory. The durability test confirms that very little maintenance is necessary. Additionally, a CFD model for the outflow of the neutral gas was designed, tested and compared with experimental data. The model reproduces the experimental results concerning mass flow rate, gas velocity and outflow pattern with a reasonable accuracy. 
Two new spring-driven valves will be installed into the vacuum vessel of AUG during the maintenance campaign 2016. Operation of these valves is foreseen for 2017.

\section{REFERENCES}

${ }^{1}$ T.C. Hender, J.C: Wesley, J. Bialek, A. Bondeson, A.H. Boozer, Nucl. Fusion 47, 128-202 (2007)

${ }^{2}$ H.M. Smith, T. Feher, T. Fülöp, K. Gal, E. Verwichte, Plasma Phys. Control. Fusion 51, 124008 (2009)

${ }^{3}$ R. Jaspers, N.J. Lopes Cardozo, F.C. Schuller, K.H. Finken, T. Grewe, Nucl Fusion 36, 367 (1996)

${ }^{4}$ G. Pautasso, C.J. Fuchs, O. Gruber, C.F. Maggi, M. Maraschek, Nucl. Fusion 47, 900 (2007)

${ }^{5}$ D.G. Whyte, M. Bakthiari, R. Granetz, V. Izzo, J. Terry, Nucl. Materials 363,1160-1167 (2007)

${ }^{6}$ E.M. Hollmann, T.C. Jernigan, M. Groth, D.G. Whyte, D.S. Gray, Nucl. Fusion 45, 1046 (2005)

${ }^{7}$ L.R. Baylor, S.K. Combs, C.R. Foust, T.C.Jernigan, S.J. Meitner, Nucl. Fusion 49, 085013 (2009)

${ }^{8}$ S.K. Combs, S.J. Meitner, L.R. Baylor, J.B. Caughman, N. Commaux, Transactions on Plasma Science 38, 3 (2010)

${ }^{9}$ M. Lehnen, A. Alonso, G. Arnoux, N. Baumgarten, S.A. Bozhenkov, Nucl. Fusion 51, 123010 (2011)

${ }^{10}$ P.C. de Vries, G. Arnoux, A. Huber, J. Flanagan, M. Lehnen, Plasma Phys. Control. Fusion 54, 124032 (2012)

${ }^{11}$ A.J. Thornton, K.J. Gibson, I.T. Chapman, J.R. Harrison, A. Kirk, Nucl. Fusion 52, 063018 (2012)

${ }^{12}$ S.A. Bozhenkov, K.H. Finken, M. Lehnen, R.C. Wolf, Rev. Sci. Instrum. 78, 033503 (2007)

${ }^{13}$ C. Reux, J. Bucalossi, F. Saint-Laurent, C. Gil, P. Moreau, P. Maget, Nucl. Fusion 50, 095006 (2010)

${ }^{14}$ R. Neu, V. Bobkov, A. Bock, M. Bernert, M. Beurskens, Trans. on Plasma Science 99, 1-9 (2016)

${ }^{15}$ U. Kruezi, P.D. Morgan, M. Lehnen, S. Bozhenkov, S. Jachmich, EFDA-JET-CP(09)06/55 (2009)

${ }^{16}$ G. Pautasso, A. Mlynek, M. Bernert, K. Mank, A. Herrmann, Nucl. Fusion 55, 033015 (2015)

${ }^{17}$ M.Dibon, G. Pautasso, M. Griener, A. Herrmann, V. Mertens, R. Neu, B. Ploeckl, Piezo-driven valve for disruption mitigation studies in tokamaks, to be published in Fusion Engineering and Design

${ }^{18}$ http://www.schnorr.de/fileadmin/downloads/de/schnorr_pb_de_s10-19.pdf

${ }^{19}$ http://www.witzenmann.de/en/media/Manual_of_metal_bellows_0441e_S_95_115_2_04_10_20_download.pdf

${ }^{20}$ https://www.piceramic.com/en/products/piezoceramic-actuators/linear-actuators/p-882-p-888-picma-stack-multilayer-piezo-actuators-100810/

${ }^{21}$ K.H. Finken, M. Lehnen, S.A. Bozhenkov, Nucl. Fusion 51, 033007 (2011)

${ }^{22}$ https://www.phantomhighspeed.com/Products/v-Series-Cameras/v711 